Article

\title{
A Lay-User Assessment of Hepatitis C Virus Self-Testing Device Usability and Interpretation in Johannesburg, South Africa
}

\author{
Mohammed Majam ${ }^{1}$, Alex Fischer ${ }^{1}$, Elena Ivanova Reipold ${ }^{2}$, Naleni Rhagnath ${ }^{1}$, Vanessa Msolomba ${ }^{1}$ iD \\ and Samanta T. Lalla-Edward $1, *$ (D) \\ 1 Ezintsha, Faculty of Health Sciences, University of the Witwatersrand, Johannesburg 2193, South Africa; \\ mmajam@ezintsha.org (M.M.); fischermHealth@gmail.com (A.F.); nrhagnath@ezintsha.org (N.R.); \\ vmsolomba@ezintsha.org (V.M.) \\ 2 Foundation for Innovative New Diagnostics, 1202 Geneva, Switzerland; elena.ivanova@finddx.org \\ * Correspondence: slallaedward@ezintsha.org; Tel.: +27-826-172-490
}

check for

updates

Citation: Majam, M.; Fischer, A.; Ivanova Reipold, E.; Rhagnath, N.; Msolomba, V.; Lalla-Edward, S.T. A Lay-User Assessment of Hepatitis C Virus Self-Testing Device Usability and Interpretation in Johannesburg, South Africa. Diagnostics 2021, 11, 463. https://doi.org/10.3390/ diagnostics 11030463

Academic Editor: Elisa Martró

Received: 15 February 2021

Accepted: 5 March 2021

Published: 7 March 2021

Publisher's Note: MDPI stays neutral with regard to jurisdictional claims in published maps and institutional affiliations.

Copyright: (c) 2021 by the authors. Licensee MDPI, Basel, Switzerland. This article is an open access article distributed under the terms and conditions of the Creative Commons Attribution (CC BY) license (https:// creativecommons.org/licenses/by/ $4.0 /)$.
Abstract: Only 20\% of people with hepatitis C virus (HCV) know their status. In low-income countries diagnosis is under $10 \%$. Self-testing for HCV antibodies (HCVST) could expand the coverage of $\mathrm{HCV}$ testing services. Currently, there are no stringent regulatory authority (SRA) approved HCVSTs, therefore lay-user usability of three prototype kits was assessed. This was a crosssectional observational study conducted with 171 (CareStart $n=60$, Bioline $n=52$, First Response $\mathrm{n}=59$ ) participants. Participants were given one of the three HCVST kits with only instructions for use (IFU) and asked to perform the test in front of a professional trained in rapid diagnostic tests (RDT). Usability indices were calculated based on the correctness of performing each step of the product-specific process followed by contrived results interpretation and a post-test interview. The usability index was 93.9\% for CareStart, 90.7\% for Bioline and 94.9\% for First Response. Most errors were on incorrect handwashing, sample collection and transfer to the test device. An average of $93.1 \%$ of contrived results were correctly interpreted, with most errors related to interpreting invalid results. Most participants $(n=167)$ stated they would visit a clinic after a positive result. With negative results, nearly half $(28 / 60(46.7 \%))$ stated they should condomize, while just over two-thirds of participants that used Bioline (35/52 (67.3\%)) and First Response (38/59 (64.4\%)) said they should re-test. Most participants $(n=162)$ found the devices easy to use. Participants liked that self-testing was fast, private and convenient, however there were some confusion with IFU steps and pictures, finger-pricking with the lancet, collecting blood after the finger-prick, and transferring the sample/buffer. Prototype HCVST kits exhibit high usability and result interpretation by lay-users, and should be considered for SRA approval.

Keywords: HCV; rapid diagnostic test; viral hepatitis

\section{Introduction}

Liver inflammation is referred to as hepatitis, and it is commonly caused by viral infections. Viral hepatitis has been on the rise since the 1990s and accounts for 1.4 million global deaths per year, comparable to tuberculosis (1.41 million deaths per year) and much higher than HIV (770,000 deaths per year) or malaria (405,000 deaths per year) [1-4]. Hepatitis B and $C$ contributes the majority of chronic viral hepatitis infections and mortalities.

In 2015, an estimated 71 million people were living with hepatitis $C$ virus $(\mathrm{HCV})$ disease, and direct percutaneous exposure with infected blood led to 1.75 million new infections annually, often via the sharing of infected needles for injection-drug use and unsafe healthcare procedures [5]. In 2016, the World Health Assembly approved a global strategy to eliminate viral hepatitis as a public health threat, with the specific targets of reducing new infections by $90 \%$ and reducing deaths by $65 \%$, by 2030 [1,5]. There is currently no vaccine for HCV, however, direct-acting antivirals introduced in 2014 have transformed the treatment options for people living with HCV [6]. An 8-12-week 
course of oral direct-acting antivirals has been shown to cure more than $90 \%$ of treated individuals $[7,8]$.

The World Health Organisation (WHO) recommends treatment for all people living with HCV, however only $20 \%$ of people living with HCV globally know their status, and in low-income countries the diagnosis rate is less than 10\% [5,7]. An economic analysis from Mongolia, Egypt and China suggests that a population-based test and treat approach may be cost-effective [1], and the WHO now recommends focused screening in highly affected populations and in the general population in settings with high HCV prevalence [9].

While screening can be performed using simple and affordable rapid diagnostic tests (RDT), access to HCV testing services remains a major barrier to the elimination of the disease, especially among hard-to-reach rural populations and high risk populations such as men who have sex with men and people who inject drugs $[9,10]$. New strategic approaches to increase HCV testing coverage are urgently needed to reach the targets of the global strategy to eliminate viral hepatitis as a public health threat by 2030 [9].

Recently, HIV self-testing (HIVST) has been identified as a facilitator to closing the testing gap for groups at high risk of HIV [11-13]. Self-testing is an innovative screening strategy in which people can collect their own specimen, perform a test themselves, and then interpret the result independent of traditional healthcare facilities [9]. This reduces barriers to traditional testing by increasing convenience and privacy, whilst also decreasing travel and wait times [14-16].

The first HIVST kit was approved for use in 2012 by the US FDA [17], and since then a strong body of evidence showing their acceptability and usability as well as increased uptake of HIV testing though HIVST [18-24] has led to WHO's recommendation to use HIVST as an additional approach [16,25]. Since 2016, 40 countries have adopted national HIVST policies [26]. Based on extensive evidence available for HIVST, it is highly likely that self-testing for HCV antibodies (HCVST) has a potential to similarly increase the uptake of HCV testing. While regulators set out comprehensive requirements for self-test evaluations, including manufacturers needing to submit usability and performance data for prequalification or CE-marking, data and experience regarding HCVST remain limited in many parts of the world [27-29].

There is no stringent regulatory authority (SRA) approved HCVSTs, however there are some high-performance and SRA approved HCV RDTs for professional use, which may be adopted for self-testing [27,30]. Two studies evaluated the performance of oral fluid HCV RDT in the hands of untrained users and showed high agreement between the results of self-administered and research-administered RDTs [31,32], however, only one study has been published on the acceptability of HCVST. This 22-person study showed prospective acceptability towards self-testing among persons who inject drugs (PWID) in the UK [33]. Available evidence on usability, performance and acceptability of self-administered HCV RDT is very limited and there is a need for a series of evaluation studies investigating the acceptability and usability of HCVST kits in a range of HCV-prevalent settings, to guide further scale-up [27]. Evaluations conducted by the HIV Self-Testing Assessments and Research (HSTAR) programme in South Africa included usability assessments [34]. The protocol for the usability assessment of HIVST was adapted to investigate the usability of three candidate blood-based HCVST kits by lay-users, to guide manufacturers in the development of HCVST kits as they prepare for evaluations for WHO prequalification.

\section{Materials and Methods}

\subsection{Study Design}

This usability assessment was an observational cross-sectional study implemented from October 2019 to January 2020. Convenience sampling was used to recruit lay users from the general population of inner-city Johannesburg, South Africa. This evaluation of three prototype HCVST kits was directed by the protocols on self-testing which were developed based on a previously conducted usability assessment of HIVSTs in Johannesburg [35]. 
For each kit, a diverse sample size of at least 52 participants (170 in total) was recruited. Each of the HCVST kits were evaluated independently and in a systematic manner. Fingerprint scanning with a biometric enrolment system was used to ensure that participants were only enrolled for one device. Participants were included if they could provide written informed consent, were able to speak/read English, were 18 years of age or older, had no previous experience with self-testing, and were willing to provide fingerstick blood samples. People were excluded if they were practicing healthcare workers with prior experience using RDTs or had any condition (such as tremors, poor vision, or intoxication) that may have interfered with any of the study processes.

\subsection{HCVST Kits}

At the time of this evaluation, each of the HCVST kits were late-stage prototypes, packaged as intended for sale or distribution in South Africa. Each HCVST package included the manufacturer's instructions for use (IFU) and all kit components required for the self-test. Three HCVST fingerstick devices were assessed: CareStart EZ HCV (CareStart) (AccessBio, Inc., Somerset, NJ, USA), SD Bioline HCV (Bioline) (Abbott Rapid Diagnostics (Pty) Ltd., Jena, Germany) and First Response HCV Card Test (First Response) (Premier Medical Corporation Pvt Ltd., Gujarat, India). All three HCVST kits were single-use tests that are considered screening tests (i.e., all positive results would require a confirmatory $\mathrm{HCV}$ ribonucleic acid test).

\subsection{Data Collection}

After participants provided written informed consent, a study staff accompanied them to a clinical research room to simulate a private setting for conducting the HCVST. Participants were given a packaged and sealed HCVST kit, with no familiarization or demonstration, then asked to complete the self-test while observed by a healthcare worker trained in RDT use (observer). The observer monitored the testing procedure and documented the successes and errors of each participant using a product-specific semi-structured questionnaire. The observer provided no feedback or assistance during the test. After the self-test was completed, the HCVST kits were exchanged for devices that displayed contrived results for the participant to interpret. Participants did not interpret their own HCVST, as this study did not evaluate the performance of HCVSTs.

Usability is a component of $\mathrm{WHO}$ prequalification therefore there have been a variety of usability studies for HIVSTs, based on the WHO prequalification guidelines for HIVST [18-24,32]. There is no standardized validated questionnaire for conducting HCVST usability assessments, however a recent study in South Africa used product-specific semistructured questionnaires to conduct usability assessments on 7 HIVSTs with lay-users in the inner-city of Johannesburg [35]. Similar to this study, we have evaluated usability with a 3-part questionnaire that includes a usability index (based on a HCVST process checklist), the interpretation of contrived results and a post-test survey.

\subsubsection{Usability Index}

For each HCVST, the usability index was calculated with a product-specific yes/no checklist that corresponded to all of the HCVST steps as outlined in each device's IFU. The successful steps were presented as a frequency and percentage, and average of all successful steps was used to calculate the total usability index for each HCVST [35]. Some steps, such as Did the study participant have difficulty with twisting the sterile tab? had a negative inflection, so the 'No' response was used in the final usability index calculation. The final usability indices were presented as a percentage, from $0.0 \%$ (not usable) to $100.0 \%$ (very usable), with scores above $85 \%$ considered excellent [35-37]

\subsubsection{Interpreting Contrived Results}

Non-functional devices had been modified by the manufacturer to display the possible outcomes from their HCVST device and these contrived results were used to evaluate 
each participants' ability to correctly interpret each of the devices' possible results: (1) non-reactive/negative; (2) reactive/positive; (3) weak reactive/weak positive (Bioline and First Response only); (4) invalid (no control line) and (5) invalid (T-line). Trained study staff observed the interpretation of the contrived results and documented all of the correctly interpreted results.

All of the participants' HCVST devices were discarded right after the self-testing procedure and before the HCVST results appeared. Participants were not informed of their HCVST results, nor were these results interpreted or recorded anywhere. Participants that wanted to formally test for $\mathrm{HCV}$ were referred to the closest healthcare facilities where testing was available.

\subsubsection{Post-Test Survey}

After completing the HCVST and interpreting the contrived results, participants were asked what they should do following positive, negative or inconclusive results, as IFUs provided recommendations for each of the possible results. Participants were also asked about their perceptions of the HCVST and the testing experience, including their most favourite and least favourite aspects of the HCVST.

\subsection{Data Analysis}

For each HCVST, data from the product-specific semi-structured questionnaires were transferred to an Excel database by the research team. Data were cleaned and coded in Excel (Microsoft Corp., Redmond, WA, USA) then quantitative data was analysed with descriptive statistics.

\section{Results}

\subsection{Demographics}

The participant demographics are presented in Table 1 . The majority of participants for each device were South African (CareStart: 57/60 (95.0\%); Bioline: 48/52 (92.3\%); First Response: $57 / 59(96.6 \%)$ ), and just over half of the participants for each assessment were male (CareStart: 33/60 (55.0\%); Bioline: 30/52 (57.7\%); First Response: 30/59 (50.8\%)). Participant age ranges varied slightly between assessments: CareStart assessment had $12 / 60(20.0 \%)$ below 25 years of age, 32/60 (53.3\%) participants between 26 and 35 years old, and 16/60 (26.7\%) above 35 years; Bioline had 19/52 (36.5\%) below 25 years of age, 18/52 (34.6\%) participants between 26 and 35 years old, and 15/52 (28.8\%) over 35 years old; and First Response had 26/59 (44.1\%) below 25 years of age, 20/52 (33.9\%) participants between 26 and 35 years old, and 13/59 (22.0\%) over 35 years old. For each assessment, the most common education level was secondary education (CareStart: 25/60 (41.7\%); Bioline: 25/52 (53.9\%); First Response: $23 / 59(39.0 \%)$ ) and the majority of participants were unemployed (CareStart: 35/60 (58.3\%); Bioline: 32/52 (61.5\%); First Response: 44/59 (74.6\%)).

Table 1. Participant demographics.

\begin{tabular}{cccc}
\hline Demographic & $\begin{array}{c}\text { CareStart } \\
\mathbf{n}(\%)\end{array}$ & $\begin{array}{c}\text { Bioline } \\
\mathbf{n}(\%)\end{array}$ & $\begin{array}{c}\text { First Response } \\
\mathbf{n}(\%)\end{array}$ \\
\hline Total $\mathbf{n}$ & $60(100.0)$ & $52(100.0)$ & $59(100.0)$ \\
Nationality & & & \\
South African & $57(95.0)$ & $48(92.3)$ & $57(96.6)$ \\
Zimbabwean & $3(5.0)$ & $3(5.8)$ & $2(4.3)$ \\
Other & $8(4.0)$ & $1(1.9)$ & $0(0.0)$ \\
Sex & & & \\
Female & $27(45.0)$ & $22(42.3)$ & $29(49.2)$ \\
Male & $33(55.0)$ & $30(57.7)$ & $30(50.8)$ \\
\hline
\end{tabular}


Table 1. Cont.

\begin{tabular}{cccc}
\hline Demographic & $\begin{array}{c}\text { CareStart } \\
\mathbf{n}(\mathbf{\%})\end{array}$ & $\begin{array}{c}\text { Bioline } \\
\mathbf{n}(\mathbf{\%})\end{array}$ & $\begin{array}{c}\text { First Response } \\
\mathbf{n} \mathbf{( \% )}\end{array}$ \\
\hline Age & & & \\
18-25 years old & $12(20.0)$ & $19(36.5)$ & $26(44.1)$ \\
26-35 years old & $32(53.3)$ & $18(34.6)$ & $20(33.9)$ \\
36-45 years old & $12(20.0)$ & $10(19.2)$ & $12(20.3)$ \\
46-55 years old & $4(6.7)$ & $3(5.8)$ & $0(0.0)$ \\
Over 55 years old & $0(0.0)$ & $2(3.8)$ & $1(1.7)$ \\
Education Level & & & \\
Primary & $18(30.0)$ & $7(13.5)$ & $23(32.2)$ \\
Secondary & $25(41.7)$ & $28(53.9)$ & $17(28.8)$ \\
Tertiary & $17(28.3)$ & $17(32.7)$ & $2(3.4)$ \\
Employment Status & & & $44(74.6)$ \\
Employed & $22(36.7)$ & $10(19.2)$ & $13(22.0)$ \\
Unemployed & $35(58.3)$ & $32(61.5)$ & $10(19.2)$ \\
Student & $3(5.0)$ & & \\
\hline
\end{tabular}

Abbreviations: $\mathrm{n}$-number; \%-percentage.

\subsection{Usability Index}

The usability index for each HCVST is fully described below and in Table 2. Direct comparisons between the different HCVSTs should not be made, as each usability checklist applied product-specific steps to calculate each usability index.

Table 2. Usability checklists and index.

\begin{tabular}{|c|c|c|c|}
\hline Usability Checklists & $\begin{array}{l}\text { Yes } \\
\text { n }(\%)\end{array}$ & $\begin{array}{l}\text { No } \\
\text { n }(\%)\end{array}$ & $\begin{array}{l}\text { Usability Index } \\
\text { (\%) }\end{array}$ \\
\hline \multicolumn{4}{|l|}{ CareStart } \\
\hline 1. Did the study participant read/use the information sheet? & $60(100.0)$ & $0(0.0)$ & 100.0 \\
\hline 2. Did the study participant select a finger and firmly massage for 5-10 s? & $56(93.3)$ & $4(6.7)$ & 93.3 \\
\hline 3. Did the study participant clean fingertip with alcohol swab then air dry? & $51(85.0)$ & $9(15.0)$ & 85.0 \\
\hline $\begin{array}{l}\text { 4. Was it difficult for the study participant to remove the test } \\
\text { content from the foil pouch? }\end{array}$ & $0(0.0)$ & $60(100.0)$ & 100 \\
\hline 5. Did the study participant have difficulty with twisting the sterile tab? & $1(1.7)$ & $59(98.3)$ & 98.3 \\
\hline 6. Did the study participant have difficulty with pulling the sterile tab? & $1(1.7)$ & $59(98.3)$ & 98.3 \\
\hline $\begin{array}{l}\text { 7. Was the study participant able to push firmly } \\
\text { against the side of the finger? }\end{array}$ & $60(100.0)$ & $0(0.0)$ & 100.0 \\
\hline $\begin{array}{l}\text { 8. Did the study participant squeeze behind the } \\
\text { sample site to form a blood droplet? }\end{array}$ & $58(96.7)$ & $2(3.3)$ & 96.7 \\
\hline $\begin{array}{l}\text { 9. Did the study participant manage to fill the tube with the } \\
\text { correct volume of blood? }\end{array}$ & $48(80.0)$ & $12(20.0)$ & 80 \\
\hline $\begin{array}{l}\text { 10. Did the study participant place the device on a flat surface and rotate } \\
\text { the arm until it clicks to release the blood? }\end{array}$ & $56(93.3)$ & $4(6.7)$ & 93.3 \\
\hline 11. Did the study participant make sure that all blood is on the test strip? & $50(83.3)$ & $10(16.7)$ & 83.3 \\
\hline $\begin{array}{l}\text { 12. Was the study participant use their thumb to push the button down } \\
\text { firmly until it clicks to release buffer? }\end{array}$ & $59(98.3)$ & $1(1.7)$ & 98.3 \\
\hline Total usability index & & & 93.9 \\
\hline
\end{tabular}


Table 2. Cont.

\begin{tabular}{|c|c|c|c|}
\hline Usability Checklists & $\begin{array}{l}\text { Yes } \\
\text { n }(\%)\end{array}$ & $\begin{array}{l}\text { No } \\
\mathrm{n}(\%)\end{array}$ & $\begin{array}{l}\text { Usability Index } \\
\text { (\%) }\end{array}$ \\
\hline \multicolumn{4}{|l|}{ Bioline } \\
\hline 1. Did the study participant read/use the information sheet? & $52(100.0)$ & $0(0.0)$ & 100.0 \\
\hline $\begin{array}{l}\text { 2. Was it difficult for the study participant to remove } \\
\text { the test device from the foil pouch? }\end{array}$ & $0(0.0)$ & $52(100.0)$ & 100.0 \\
\hline $\begin{array}{l}\text { 3. Did the study participant successfully place material on } \\
\text { flat surface and open all pouches and cap? }\end{array}$ & $52(100.0)$ & $0(0.0)$ & 100.0 \\
\hline 4. Did the study participant wash hands in warm water and dry? & $45(86.5)$ & $7(13.5)$ & 86.5 \\
\hline 5. Did the study participant correctly choose the ring or middle finger? & $51(98.1)$ & $1(1.9)$ & 98.1 \\
\hline 6. Did the study participant massage and warm their hands? & $51(98.1)$ & $1(1.9)$ & 98.1 \\
\hline $\begin{array}{l}\text { 7. Did the study participant clean the finger with alcohol } \\
\text { swab and let it dry? }\end{array}$ & $51(98.1)$ & $1(1.9)$ & 98.1 \\
\hline $\begin{array}{l}\text { 8. Did the study participant successfully press down firmly } \\
\text { to prick their skin? }\end{array}$ & $45(86.5)$ & $7(13.5)$ & 86.5 \\
\hline $\begin{array}{l}\text { 9. Did the study participant successfully wipe away the first drop of blood } \\
\text { with tissue and then rub create a second large drop of blood? }\end{array}$ & $35(67.3)$ & $17(32.7)$ & 67.3 \\
\hline $\begin{array}{l}\text { 10. Did the study participant use the specimen dropper to } \\
\text { collect the drop of blood? }\end{array}$ & $43(82.7)$ & $9(17.3)$ & 82.7 \\
\hline $\begin{array}{l}\text { 11. Did the study participant successfully dispense the whole blood into } \\
\text { the round specimen well (marked } S^{\prime} \text { ) of the device? }\end{array}$ & $44(84.6)$ & $8(15.4)$ & 84.6 \\
\hline 12. Did the study participant successfully apply in plaster? & $46(88.5)$ & $6(11.5)$ & 88.5 \\
\hline $\begin{array}{l}\text { 13. Was the study participant able to twist and pull cap to open assay } \\
\text { diluent, then dispense all the assay diluent tube into the } \\
\text { square well of the device? }\end{array}$ & $46(88.5)$ & $6(11.5)$ & 88.5 \\
\hline Total usability index & & & 90.7 \\
\hline \multicolumn{4}{|l|}{ First Response } \\
\hline 1. Did the study participant read/use the information sheet? & $59(100.0)$ & $0(0.0)$ & 100.0 \\
\hline $\begin{array}{l}\text { 2. Did the study participant wash hands in warm water and soap then dry } \\
\text { and check the expiry date of the kit? }\end{array}$ & $49(83.0)$ & $10(17.0)$ & 83.0 \\
\hline $\begin{array}{l}\text { 3. Was it difficult for the study participant to remove the test } \\
\text { device from the foil pouch? }\end{array}$ & $5(8.5)$ & $54(91.5)$ & 91.5 \\
\hline $\begin{array}{l}\text { 4. Did the participant wipe fingertip using alcohol } \\
\text { swab and allow to dry }(15 \mathrm{~s}) \text { ? }\end{array}$ & $54(91.5)$ & $5(8.5)$ & 91.5 \\
\hline $\begin{array}{l}\text { 5. Did the study participant successfully remove the clear } \\
\text { protective cap of the sterile safety lancet? }\end{array}$ & $59(100.0)$ & $0(0.0)$ & 100.0 \\
\hline $\begin{array}{l}\text { 6. Did the study participant successfully press down } \\
\text { firmly to prick their skin? }\end{array}$ & $59(100.0)$ & $0(0.0)$ & 100.0 \\
\hline $\begin{array}{l}\text { 7. Did the study participant gently squeeze fingertip to } \\
\text { obtain a large drop of blood? }\end{array}$ & $59(100.0)$ & $0(0.0)$ & 100.0 \\
\hline $\begin{array}{l}\text { 8. Did the study participant successfully wipe away the } \\
\text { first drop of blood with dry swab? }\end{array}$ & $51(86.4)$ & 8 (13.6) & 86.4 \\
\hline $\begin{array}{l}\text { 9. Did the study participant gently squeeze fingertip } \\
\text { to obtain a large second drop of blood? }\end{array}$ & $56(94.9)$ & $3(5.1)$ & 94.9 \\
\hline $\begin{array}{l}\text { 10. Did the study participant use the specimen dropper to } \\
\text { collect the drop of blood? }\end{array}$ & $59(100.0)$ & $0(0.0)$ & 100.0 \\
\hline
\end{tabular}


Table 2. Cont.

\begin{tabular}{|c|c|c|c|}
\hline Usability Checklists & $\begin{array}{l}\text { Yes } \\
\text { n }(\%)\end{array}$ & $\begin{array}{l}\text { No } \\
\text { n }(\%)\end{array}$ & $\begin{array}{l}\text { Usability Index } \\
\qquad(\%)\end{array}$ \\
\hline $\begin{array}{l}\text { 11. Did the study participant successfully dispense the whole blood into } \\
\text { the round specimen well (marked ' } S \text { ') of the device? }\end{array}$ & $53(89.8)$ & $6(10.2)$ & 89.8 \\
\hline $\begin{array}{l}\text { 12. Was the study participant able to twist and pull cap } \\
\text { to open the assay buffer? }\end{array}$ & $59(100.0)$ & $0(0.0)$ & 100.0 \\
\hline $\begin{array}{l}\text { 13. Was the study participant able to add } 2 \text { drops of assay } \\
\text { buffer into the specimen well? }\end{array}$ & $57(96.6)$ & $2(3.4)$ & 96.6 \\
\hline Total usability index & & & 94.9 \\
\hline
\end{tabular}

Abbreviations: $\mathrm{n}$-number; \%—percentage; IFU—information for use.

\subsubsection{CareStart}

The overall usability index of CareStart was 93.9\%. All participants read and used the information sheet, while 56/60 (93.3\%) selected a finger and firmly massaged it for 5-10 s and 51/60 (85.0\%) cleaned the fingertip with the alcohol swab then let it air dry. None of the participants had difficulty removing the test content from the foil pouch, however one participant had difficulty twisting the sterile tab and another one had difficulty pulling the sterile Table All participants pushed firmly against the side of the finger, 58/60 (96.7\%) participants squeezed behind the sample site to form a blood droplet and 48/60 (80.0\%) managed to fill the tube with the correct volume of blood. Most participants (56/60 (93.3\%)) placed the device on a flat surface and rotated the arm until it clicked to release the blood, $50 / 60(83.3 \%)$ made sure that all of the blood was on the test strip and 59/60 (98.3\%) participants used their thumb to push the button down firmly until it clicked to release the buffer.

\subsubsection{Bioline}

For Bioline, the overall usability index was $90.7 \%$. All participants $(52 / 52(100.0 \%))$ read and used the information sheet, none $(0 / 52(0.0 \%))$ had difficulty removing the test content from the foil pouch and all participants (52/52 (100.0\%)) successfully placed the kit materials on a flat surface, then opened all pouches and cap. Most (45/52 (86.5\%)) participants washed their hands in warm water and dried them, then 51/52 (98.1\%) participants correctly chose the ring or middle finger, massaged and warmed their hands, and cleaned the finger with an alcohol swab then let it dry. Most (45/52 (86.5\%)) participants successfully pressed down firmly to prick their skin, 35/52 (67.3\%) participants wiped away the first drop of blood, then rubbed to create a second large drop of blood, and 43/52 $(82.7 \%)$ participants used the specimen dropper to collect the drop of blood. Forty-four out of fifty-two $(84.6 \%)$ participants successfully dispensed the whole blood into the round specimen well of the device, $46 / 52(88.5 \%)$ participants successfully applied the plaster and $46 / 52(88.5 \%)$ participants were able to twist and pull the cap to open the assay diluent, then dispense all the assay diluent tube into the square well of the device.

\subsubsection{First Response}

The overall usability index was $94.9 \%$. All participants $(59 / 59(100.0 \%))$ read and used the information sheet and $49 / 59$ (83.0\%) participants washed their hands in warm water and soap then dried and checked the expiry date of the kit. Only 5/59 (8.5\%) participants had difficulty removing the test content from the foil pouch, and 54/59 (91.5\%) participants wiped their fingertip with an alcohol swab and allowed it to dry. All (59/59 $(100.0 \%)$ ) participants successfully removed the clear protective cap of the sterile safety lancet, successfully pressed down firmly to prick their skin, and gently squeezed their fingertip to obtain a large drop of blood. Most (51/59 (86.4\%)) successfully wiped away the first drop of blood with the dry swab, 56/59 (94.9\%) gently squeezed their fingertip to obtain a large second drop of blood and all (59/59 (100.0\%)) participants used the specimen 
dropper to collect the drop of blood. Majority (53/59 (89.9\%)) successfully dispensed the whole blood into the round specimen well of the device, all (59/59 (100.0\%)) participants were able to twist and pull the cap to open the assay buffer. Lastly, almost all (57/59 $(96.6 \%))$ successfully added 2 drops of assay buffer into the specimen well.

\subsection{Interpreting Contrived Results}

\subsubsection{CareStart}

For CareStart, $90.0 \%$ of the contrived results were correctly interpreted by participants. Most participants correctly interpreted the non-reactive/negative results (58/60 $(96.7 \%))$, the reactive/positive results $(58 / 60(96.7 \%))$ and the invalid (no control line) results $(54 / 60(90.0 \%))$, however the invalid (T-line) results were correctly interpreted by fewer participants $(46 / 60(76.7 \%))$. There were no weak reactive/weak positive contrived results available to interpret.

\subsubsection{Bioline}

Here $95.8 \%$ of the contrived results were correctly interpreted by participants. All participants (52/52 (100.0\%)) correctly interpreted the reactive/positive results and the invalid (no control line) results, 49/52 (94.2\%) correctly interpreted the non-reactive/negative results, 50/52 (96.2\%) correctly interpreted the weak reactive/weak positive results and $46 / 52(88.5 \%)$ correctly interpreted the invalid (T-line) results.

\subsubsection{First Response}

For First Response, $97.3 \%$ of the contrived results were correctly interpreted by participants. All participants (59/59 (100.0\%)) correctly interpreted the non-reactive/negative results and the reactive/positive results, while 58/59 (98.3\%) correctly interpreted the weak reactive/weak positive and invalid (no control line) results, and 53/59 (89.8\%) correctly interpreted the invalid (T-line) results.

These results are presented in Table 3.

Table 3. Usability outcomes and user perceptions.

\begin{tabular}{|c|c|c|c|}
\hline Outcomes & $\begin{array}{c}\text { CareStart } \\
(n=60)\end{array}$ & Bioline $(n=52)$ & $\begin{array}{l}\text { First Response } \\
\qquad(\mathrm{n}=59)\end{array}$ \\
\hline & n (\%) & n (\%) & n (\%) \\
\hline \multicolumn{4}{|l|}{ Interpreting contrived results } \\
\hline Non-reactive/Negative & $58(96.7)$ & $49(94.2)$ & $59(100.0)$ \\
\hline Reactive/Positive & $58(96.7)$ & $52(100.0)$ & $59(100.0)$ \\
\hline Weak reactive/Weak positive & $\mathrm{n} / \mathrm{a}$ & $50(96.2)$ & $58(98.3)$ \\
\hline Invalid (no control line) & $54(90.0)$ & $52(100.0)$ & $58(98.3)$ \\
\hline Invalid (T-line) & $46(76.7)$ & $46(88.5)$ & $53(89.8)$ \\
\hline Average & $54.0(90.0)$ & $49.8(95.8)$ & $57.4(97.3)$ \\
\hline \multicolumn{4}{|l|}{ What to do after HCVST } \\
\hline \multicolumn{4}{|l|}{ If Negative/Non-Reactive } \\
\hline Do not know & $8(13.3)$ & $0(0.0)$ & $0(0.0)$ \\
\hline Condomize & $28(46.7)$ & $0(0.0)$ & $4(6.8)$ \\
\hline Retest & $0(0.0)$ & $35(67.3)$ & $38(64.4)$ \\
\hline Other & $24(40.0)$ & $17(32.7)$ & $17(28.8)$ \\
\hline \multicolumn{4}{|l|}{ If Positive/Reactive } \\
\hline Visit clinic & $58(96.7)$ & $52(100.0)$ & $57(96.6)$ \\
\hline Other & $2(3.3)$ & $0(0.0)$ & $2(3.4)$ \\
\hline \multicolumn{4}{|l|}{ If Invalid/test did not work } \\
\hline Visit clinic & $19(31.7)$ & $24(46.2)$ & $13(23.7)$ \\
\hline Retest & 38 (63.3) & $28(53.8)$ & $45(76.3)$ \\
\hline Other & $3(5.0)$ & $0(0.0)$ & $0(0.0)$ \\
\hline
\end{tabular}


Table 3. Cont

\begin{tabular}{|c|c|c|c|}
\hline Outcomes & $\begin{array}{c}\text { CareStart } \\
(\mathrm{n}=60)\end{array}$ & Bioline $(n=52)$ & $\begin{array}{l}\text { First Response } \\
\quad(n=59)\end{array}$ \\
\hline & n $(\%)$ & n $(\%)$ & n $(\%)$ \\
\hline \multicolumn{4}{|l|}{ Participant perceptions of the HCVST process * } \\
\hline 1. Did you use the instructions sheet? & $60(100.0)$ & $51(98.1)$ & $59(100.0)$ \\
\hline 2. Were the instructions easy to follow? & $58(96.7)$ & $47(90.4)$ & $59(100.0)$ \\
\hline 3. Was the device easy to use? & $58(96.7)$ & $45(86.5)$ & $59(100.0)$ \\
\hline 4. Did you wait the stipulated time before reading the result? & $59(98.3)$ & $51(98.1)$ & $58(98.3)$ \\
\hline 5. Were you confident with performing this test on your own? & $59(98.3)$ & $46(88.5)$ & $56(94.9)$ \\
\hline 6. Was it easy for you to INTERPRET the mock results? & $58(98.3)$ & $48(92.3)$ & $55(93.2)$ \\
\hline 7. Would you use this test again? & $50(83.3)$ & $51(98.1)$ & $55(93.2)$ \\
\hline $\begin{array}{l}\text { 8. Would you prefer to use this test at home instead of getting } \\
\text { tested at a clinic? }\end{array}$ & $52(86.7)$ & $42(80.8)$ & $49(83.1)$ \\
\hline \multicolumn{4}{|l|}{ Favourite things about the HCVST } \\
\hline Easy to use & $52(86.7) *$ & $44(84.6)$ & $54(91.5)$ \\
\hline Fast & $26(43.3)$ & $25(48.1)$ & $32(54.2)$ \\
\hline Private & $29(48.3)$ & $5(9.6)$ & $33(55.9)$ \\
\hline Convenient & $10(16.7)$ & $5(9.6)$ & $4(6.8)$ \\
\hline Other & $3(5.0)$ & $1(1.9)$ & $5(8.5)$ \\
\hline \multicolumn{4}{|l|}{ Least favourite things about the HCVST } \\
\hline No complaints & $52(86.7)^{* *}$ & $33(63.5)$ & $49(83.1)$ \\
\hline Lancet difficulties & $4(6.7)$ & $14(26.9)$ & $1(1.7)$ \\
\hline Specimen dropper/buffer difficulties & $0(0.0)$ & $2(3.8)$ & $6(10.2)$ \\
\hline Confusion about IFU steps and pictures & $1(1.7)$ & $3(5.8)$ & $3(5.1)$ \\
\hline No info on post-test guidance & $2(3.3)$ & $0(0.0)$ & $0(0.0)$ \\
\hline Other & $1(1.7)$ & $1(1.9)$ & $0(0.0)$ \\
\hline
\end{tabular}

Abbreviations: $n$-number; \%-percentage; IFU—instructions for use. Notes: * reported values are for yes answers ${ }^{* *}$ percentages may not add up to 100 as participants were able to choose multiple answers.

\subsection{Participant Knowledge of Processes Following an HCVST \\ 3.4.1. CareStart}

When CareStart participants were asked what to do after a negative HCVST result, $28 / 60(46.7 \%)$ participants would condomize, while 8/60 (13.3\%) did not know what to do and none said that they would retest at all (self-test or professional). Almost all (58/60 (96.7\%)) participants said they would visit a clinic after a positive HCVST result, and if the test was invalid or did not work, 19/60 (31.7\%) said they would visit a clinic, while 38/60 $(63.3 \%)$ said they would retest.

\subsubsection{Bioline}

Bioline participants, when asked what to do after a negative HCVST result, 35/52 $(67.3 \%)$ participants would retest, while $0 / 52(0.0 \%)$ did not know what to do and none said that they would condomize. All (52/52 (100.0\%)) participants stated that they would visit a clinic after a positive HCVST, and if the test was invalid or did not work, 24/52 $(46.2 \%)$ said they would visit a clinic, while $28 / 52$ (53.8\%) said they would retest.

\subsubsection{First Response}

Of the First Response participants who were asked what to do after a negative HCVST result, 38/59 (64.4\%) participants would retest, while all knew what to do and 4/59 (6.8\%) said that they would condomize. Almost all (57/59 (96.6\%)) participants stated that they would visit a clinic after a positive HCVST, and if the test was invalid or did not work, $13 / 59(23.7 \%)$ would visit a clinic, while $45 / 59$ (76.3\%) said they would retest. 


\subsection{Participant Perspectives of the HCVST Process}

\subsubsection{CareStart}

All participants used the IFU, and most participants (58/60 (96.7\%)) found them easy to follow. Most participants also found the device easy to use (58/60 (96.7\%)) and were confident performing it on their own (59/60 (98.3\%)). Almost everyone (59/60 (98.3\%)) correctly identified $15 \mathrm{~min}$ as the amount of time you should wait before reading the results, and 56/59 (93.3\%) participants found it easy to interpret the mock results. When asked about future testing, 50/60 (83.3\%) participants said they would use this test again, 52/60 $(86.7 \%)$ said they would prefer to use this HCVST at home instead of going to a clinic and $55 / 60(91.7 \%)$ said they would recommend this test to someone else.

When asked about the advantages of HCVST, 52/60 (86.7\%) participants liked that it was easy to use, $26 / 60(43.3 \%)$ liked that it was fast, $29 / 60(48.3 \%)$ liked that it was private and 10/60 (16.7\%)) liked that it was convenient. Most participants (52/60 (86.7\%)) had no complaints about the testing process, however $4 / 60(6.7 \%)$ had difficulties pricking themselves with the lancet, $1 / 60(2.7 \%)$ was confused about the IFU steps and pictures and $2 / 60(3.3 \%)$ did not like the lack of information on what to do after the test.

\subsubsection{Bioline}

Almost all (51/52 (98.1\%)) participants used the IFU, and 47/52 (90.4\%) found it easy to follow. For the device, 45/52 (86.5\%) participants found it easy to use and 46/52 (88.5\%) participants were confident performing the test on their own. Almost everyone $(51 / 52$ $(98.1 \%)$ ) correctly identified the 15 -min wait before reading the results and 48/52 (92.3\%) found the contrived results easy to interpret. For future testing, 51/52 (98.1\%) said they would use this test again, 42/52 (80.8\%) said they would prefer to use the HCVST at home instead of going to a clinic and $51 / 52(98.1 \%)$ said they would recommend this test to a sexual partner or friend.

When asked about advantages of HCVST, 44/52 (84.6\%) liked that it was easy to use, $25 / 52(48.1 \%)$ liked that it was fast and 5/52 (9.6\%) participants liked that it was both private and convenient. Nearly two-thirds (33/52 (63.5\%)) of the participants had no complaints about the HCVST process, however 14/52 (26.9\%) had difficulties pricking themselves with the lancet, $2 / 52(3.8 \%)$ had difficulties transferring the specimen to the buffer and 3/52 (5.8\%) were confused about the IFU steps and pictures.

\subsubsection{First Response}

All participants $(59 / 59(100.0 \%))$ used the IFU, found the instructions easy to follow, and the device easy to use, while 56/59 (94.9\%) participants were confident performing the test on their own. Most participants (58/59 (98.3\%)) correctly identified the 15-min wait before reading the results and 55/58 (93.2\%) found the mock results easy to interpret. When asked about future testing, 55/58 (93.2\%) said they would use this test again, 49/59 (83.1\%) said they would prefer to use this HCVST at home instead of testing at a clinic and $56 / 59(94.9 \%)$ participants would recommend this test to a sexual partner or friend.

When asked about advantages of the HCVST process, 54/59 (91.5\%) liked that it was easy to use, $32 / 59(54.2 \%)$ liked that it was fast, 33/59 (55.9\%) liked that it was private and $4 / 59(6.8 \%)$ liked the convenience. Most participants (49/59 (83.1\%)) had no complaints about the HCVST, however 6/59 (10.2\%) had difficulties transferring the specimen to the buffer, $3 / 59(5.1 \%)$ were confused about the IFU steps and pictures and $1 / 59(1.7 \%)$ experienced issues with the lancet.

\section{Discussion}

This is the first study evaluating the usability of prototype blood based HCVST kits. At the time of the study, two evaluations of self-administered professional use oral fluid HCV RDTs [31,32] and one qualitative study on the acceptability had been published [33], however no reports had been published on HCVST usability to provide context for our findings. There is, however, a strong evidence base for the usability of HIVSTs, and their 
evaluations followed a very similar methodology. In early 2020, the HSTAR programme published an evaluation of 7 HIVSTs in the same region of Johannesburg, including 5 blood based HIVSTs [35]. These blood based HIVSTs had an average usability index of $93.6 \%$, similar to the average usability index of the HCVST kits, which was $93.1 \%$.

The high usability indices of the three prototype HCVST kits were supported by $86.5-100.0 \%$ of the participants that self-reported the tests were easy to use, which was consistent with the $96.3 \%$ of blood-based HIVST users from Johannesburg that also found their tests easy to use [35]. These results were also similar to other HIVST usability evaluations, including the $91 \%$ of Exacto HIVST users from the Central African Republic and the $94.4 \%$ of INSTI HIVST users in Kenya, who reported their respective HIVSTs were easy to use [38,39].

While participants reported that ease of use was the most important advantage of self-testing, participants from each prototype HCVST group liked that self-testing was fast, private and convenient. Similar attributes from HIVST studies have suggested that self-testing can remove barriers found in traditional clinic-based testing processes [14-16]. For HCV, barriers to testing include stigma and discrimination, which suggests that the privacy offered by HCVSTs may facilitate testing [9]. In South Africa specifically, a recent study among PWID identified barriers to accessing HCV treatment as fear of stigma, and long waiting periods [40], both barriers that can be facilitated by the speed, privacy and convenience offered by HCVST. HCVSTs have the potential to remove barriers linked with traditional HCV testing, so obtaining SRA approval for HCVSTs will help reach the 2030 targets $[1,9,40]$, especially in key populations, like PWID.

Participants shared aspects of HCVST that they did not like, and these included unclear IFU steps and pictures, difficulties pricking themselves with the lancet, and difficulties transferring the specimen to the buffer. The lancet and specimen dropper/buffer difficulties were corroborated by the usability checklist, as steps concerning the collection of the specimen and the transfer of the specimen to the buffer were some of the only steps where more than $10 \%$ of participants made errors. The Johannesburg HIVST study identified difficulties collecting and transferring samples [35], as did an Atomo HIVST usability study in Cape Town, which reported lancing errors, the inability to collect a sufficient blood sample and transferring inadequate amounts of the sample [41]. Some of the HCV participants that cited difficulty with the IFU directly referenced the steps surrounding the collection and transfer of the specimen, which suggests that errors in specimen collection and transfer may be reduced by making clarifications/simplifications to the IFU.

On the HCVST checklists, almost $15 \%$ of participants did not wash and dry their hands according to the IFU, and over $10 \%$ of participants made mistakes wiping the first drop of blood away before collecting a sample. While these steps did not prevent the participant from completing the HCVST process, they may compromise the quality of the sample, possibly resulting in erroneous results. To see if errors in these steps would affect the accuracy of results and to determine the performance of HCVST, larger studies, similar to those for HIVST prequalification [23-25] should be conducted. While evaluation of the performance of HCVST prototypes was beyond the scope of the current study, we have assessed the ability of lay users to interpret the results of HCVST using contrived HCVST devices. For all three HCVST, contrived results were interpreted correctly by more than $90 \%$ of the participants. Invalid (T-line) results were interpreted correctly by $75-90 \%$ of the participants. The Johannesburg HIVST study did not have a contrived invalid (T-line) result, however the interpretation of contrived negative, positive, weak positive and invalid (no control) showed similarly high successful interpretation [35].

This study has shown high usability of prototype HCVST and has been useful in informing the improved development of blood based HCVST kits. While future usability studies on HCVST may lend from the methodologies described here, they should include more robust sample sizes from diverse populations and regions, especially in highprevalence settings and populations [27]. Furthermore, additional performance evaluations 
of HCVST kits will be needed primarily because high performance quality assured HCVST tools are crucial to enable further implementation research and policy development.

Lockdown restrictions to halt the spread of COVID-19, combined with over-burdened healthcare systems have led to the disruption of hepatitis screening programmes, with some countries completely halting hepatitis screening programmes [42]. Predictive models have shown that a 1-year delay in hepatitis interventions could lead to over 70,000 excess deaths by 2030, compared to the baseline scenario with no delay [43]. Currently there is no WHO recommendation on HCVST. The scaling up of HIVST during the pandemic, has been suggested to combat a similar drop in facility-based HIV screening [44], and the scaling up of HCVST could also fill the testing void due to COVID-19. It is therefore important for the $\mathrm{WHO}$ to take this into account as they consider updated guidelines on HCVST in early 2021 [45].

\section{Limitations}

The convenience sampling used in this study may have caused a sampling bias, as different proportions of sub-demographics were present between devices, specifically the participants' employment status. No key populations were involved in the study, so findings may be not applicable for these populations. The devices were evaluated in series to ensure that there was no cross-contamination, but the sampling of participants from the same community may have resulted in participants who enrolled later in the study becoming more aware of HCVST towards the end of the study. Furthermore, the participants from the same community have been previously sampled to participate in studies with HIVST. Although previous experience with any self-test excluded someone from participating in this study, they may have heard about self-testing from others in the community.

Although data collection was directed by previous HIVST usability assessments, there is no standardized usability test for HCVST, and at the time of data collection, there were no published studies of HCVST to compare methodologies with. The semi-structured productspecific checklists allowed for the quantification of usability through a usability index, however each device checklist was slightly different, which prohibited direct comparisons between devices. No diagnostic results were collected, so there was no way to determine whether user errors observed during study actually led to erroneous test results.

\section{Conclusions}

This HCVST study has shown that evaluated prototype blood-based HCVST kits exhibit high usability in the hands of untrained lay-users, with respect to their usability index, contrived results interpretation, and direct user feedback. Although there are no other published usability assessments of blood-based HCVST to give context to these results, our findings are in agreement with high usability scores for HIVSTs in similar settings $[35,38-40]$. Given the high usability of these prototype HCVSTs, and their potential to remove barriers to traditional HCV testing, these findings are useful in informing the improved development of blood based HCVST kits towards SRA approval.

Author Contributions: Conceptualization, M.M., E.I.R. and N.R.; Formal analysis, M.M., A.F. and N.R.; Funding acquisition, E.I.R.; Methodology, V.M.; Writing-original draft, A.F. and S.T.L.-E.; Writing-Review and editing, M.M., A.F., E.I.R., N.R., V.M. and S.T.L.-E. All authors have read and agreed to the published version of the manuscript.

Funding: This research was funded by Unitaid, through the HEAD-start project, awarded to Foundation for Innovative New Diagnostics.

Institutional Review Board Statement: The study was conducted according to the guidelines of the Declaration of Helsinki and approved by the Human Research Ethics Committee of the University of the Witwatersrand (ethics reference number 190703) on 9 September 2019.

Informed Consent Statement: Informed consent was obtained from all subjects involved in the study. 
Data Availability Statement: The data presented in this study are available on request from the corresponding author. The data are not publicly available to maintain participant confidentiality.

Acknowledgments: We thank Access Bio Inc., Abbott Rapid Diagnostics (Pty) Ltd., and Premier Medical Corporation for providing HCVST kits and contrived tests.

Conflicts of Interest: All test kits for this assessment were provided by the manufacturers at no cost. The manufacturers had no role in the design of the study, in the collection, analyses, or interpretation of data or in the writing of the manuscript. The authors themselves declare no conflict of interest.

\section{References}

1. World Health Organization. Combating Hepatitis B and C to Reach Elimination by 2030; WHO Press: Geneva, Switzerland, 2016.

2. World Health Organization. Progress Report on HIV, Viral Hepatitis and Sexually Transmitted Infections, 2019; WHO Press: Geneva, Switzerland, 2019.

3. World Health Organization. Global Tuberculosis Report 2020; WHO Press: Geneva, Switzerland, 2020.

4. World Health Organization. World Malaria Report 2019; WHO Press: Geneva, Switzerland, 2019.

5. World Health Organization. Global Hepatitis Report 2017; WHO Press: Geneva, Switzerland, 2018.

6. Schinazi, R.; Halfon, P.; Marcellin, P.; Asselah, T. HCV direct-acting antiviral agents: The best interferon-free combinations. Liver Int. 2014, 34 (Suppl. 1), 69-78. [CrossRef]

7. Pawlotsky, J.M. New hepatitis C therapies: The toolbox, strategies, and challenges. Gastroenterology 2014, 146, 1176-1192. [CrossRef]

8. Feeney, E.R.; Chung, R.T. Antiviral treatment of hepatitis C. BMJ 2014, 348, g3308. [CrossRef]

9. World Health Organization. Guidelines on Hepatitis B and C Testing; WHO Press: Geneva, Switzerland, 2017.

10. World Health Organization. Progress Report on Access to Hepatitis C Treatment: Focus on Overcoming Barriers in Low-and MiddleIncome Countries; WHO Press: Geneva, Switzerland, 2018.

11. Johnson, C.C.; Kennedy, C.; Fonner, V.; Siegfried, N.; Figueroa, C.; Dalal, S.; Sands, A.; Baggaley, R. Examining the effects of HIV self-testing compared to standard HIV testing services: A systematic review and meta-analysis. J. Int. AIDS Soc. 2017, 20, 21594. [CrossRef] [PubMed]

12. Johnson, C.C.; Kennedy, C.; Fonner, V.; Siegfried, N.; Figueroa, C.; Dalal, S.; Sands, A.; Baggaley, R. HIV Self-Testing in Resource-Limited Settings: Regulatory and Policy Considerations. AIDS Behav. 2014, 18 (Suppl. 4), 415. [CrossRef]

13. Cohen, M.S.; Chen, Y.Q.; McCauley, M.; Gamble, T.; Hosseinipour, M.C.; Kumarasamy, N.; Hakim, J.G.; Kumwenda, J.; Grinsztejn, B.; Pilotto, J.H.; et al. Prevention of HIV-1 infection with early antiretroviral therapy. N. Engl. J. Med. 2011, 365, 493-505. [CrossRef] [PubMed]

14. Makusha, T.; Knight, L.; Taegtmeyer, M.; Tulloch, O.; Davids, A.; Lim, J.; Peck, R.; Van Rooyen, H. HIV Self-Testing Could "Revolutionize Testing in South Africa, but It Has Got to Be Done Properly": Perceptions of Key Stakeholders. PLoS ONE 2015, 10, e0122783. [CrossRef]

15. Figueroa, C.; Johnson, C.; Verster, A.; Baggaley, R. Attitudes and Acceptability on HIV Self-testing Among Key Populations: A Literature Review. AIDS Behav. 2015, 19, 1949. [CrossRef]

16. World Health Organization. Guidelines on HIV Self-Testing and Partner Notification: Supplement to Consolidated Guidelines on HIV Testing Services; WHO Press: Geneva, Switzerland, 2016.

17. FDA Approves First Over-the-Counter Home Use HIV Test Kit. Available online: https://www.natap.org/2012/newsUpdates/ 071012_03.htm (accessed on 10 February 2021).

18. Indravudh, P.; Choko, A.; Corbett, E. Scaling up HIV self-testing in sub-Saharan Africa: A review of technology, policy and evidence. Curr. Opin. Infect. Dis. 2018, 31, 14-24. [CrossRef] [PubMed]

19. Kalibala, S.; Tun, W.; Cherutich, P.; Nganga, A.; Oweya, E.; Oluoch, P. Factors associated with acceptability of HIV self-testing among health care workers in Kenya. AIDS Behav. 2014, 18 (Suppl. 4), S405-S414. [CrossRef]

20. Choko, A.T.; MacPherson, P.; Webb, E.L.; Willey, B.A.; Feasy, H.; Sambakunsi, R.; Mdolo, A.; Makombe, S.D.; Desmond, N.; Hayes, R.; et al. Uptake, accuracy, safety, and linkage into care over two years of promoting annual self-testing for HIV in Blantyre, Malawi: A community-based prospective study. PLoS Med. 2015, 12, e1001873. [CrossRef]

21. Johnson, C.; Baggaley, R.; Forsythe, S.; van Rooyen, H.; Ford, N.; Napierala Mavedzenge, S.; Corbett, E.; Natarajan, P.; Taegtmeyer, M. Realizing the potential for HIV self-testing. AIDS Behav. 2014, 18 (Suppl. 4), S391-S395. [CrossRef]

22. Krause, J.; Subklew-Sehume, F.; Kenyon, C.; Colebunders, R. Acceptability of HIV self-testing: A systematic literature review. BMC Public Health 2013, 13, 735. [CrossRef]

23. Figueroa, C.; Johnson, C.; Ford, N.; Sands, A.; Dalal, S.; Meurant, R.; Prat, I.; Hatzold, K.; Urassa, W.; Baggaley, R. Reliability of HIV rapid diagnostic tests for self-testing compared with testing by health-care workers: A systematic review and meta-analysis. Lancet HIV 2018, 5, e277-e290. [CrossRef]

24. Pai, N.P.; Sharma, J.; Shivkumar, S.; Pillay, S.; Vadnais, C.; Joseph, L.; Dheda, K.; Peeling, R.W. Supervised and unsupervised self-testing for HIV in high- and low-risk populations: A systematic review. PLoS Med. 2013, 10, e1001414.

25. World Health Organization. Technical Specifications Series for Submission to WHO Prequalification-Diagnostic Assessment: Human Immunodeficiency Virus (HIV) Rapid Diagnostic Tests for Professional Use and/or Self-Testing; World Health Organization: Geneva, Switzerland, 2017. 
26. World Health Organization. Number of Countries Adopting HIV Self-Testing Policies Rises Sharply. 25 July 2017. Available online: https:/ / www.who.int/hiv/mediacentre/news/hiv-self-testing-increases/en/ (accessed on 25 November 2020).

27. World Health Organization. Technical Specifications Series for Submission to WHO Prequalification-Diagnostic Assessment: Rapid Diagnostic Tests to Detect Hepatitis C Antibody or Antigen; World Health Organization: Geneva, Switzerland, 2019.

28. European Centre for Disease Prevention and Control. Public Health Guidance on HIV, Hepatitis B and C Testing in the EU/EEA-An Integrated Approach; ECDC: Stockholm, Sweden, 2018.

29. Eur-Lex. Regulation (EU) 2017/746 of the European Parliament and of the Council of 5 April 2017 on In Vitro Diagnostic Medical Devices and Repealing Directive 98/79/EC and Commission Decision 2010/227/EU (Text with EEA Relevance). Available online: https: / / eur-lex.europa.eu/legal-content/EN/TXT/PDF/?uri=CELEX:02017R0746-20170505\&from=EN (accessed on 3 March 2021).

30. Vetter, B.N.; Reipold, E.I.; Ongarello, S.; Audu, R.; Ige, F.A.; Alkhazashvili, M.; Chitadze, N.; Vanroye, F.; De Weggheleire, A.; Sokkab, A.; et al. Sensitivity and specificity of rapid diagnostic tests for hepatitis C virus with or without HIV coinfection: A multicentre laboratory evaluation study. J. Infect. Dis. 2020, jiaa389. [CrossRef] [PubMed]

31. Kimble, M.M.; Stafylis, C.; Treut, P.; Saab, S.; Klausner, J. Clinical evaluation of a hepatitis C antibody rapid immunoassay on self-collected oral fluid specimens. Diagn. Microbiol. Infect. Dis. 2019, 95, 149-151. [CrossRef] [PubMed]

32. Liu, L.; Zhang, M.; Hang, L.; Kong, F.; Yan, H.; Zhang, Y.; Feng, X.; Gao, Y.; Wang, C.; Ma, H.; et al. Evaluation of a new point-of-care oral anti-HCV test for screening of hepatitis C virus infection. Virol. J. 2020, 17, 14. [CrossRef] [PubMed]

33. Guise, A.; Witzel, T.C.; Mandal, S.; Sabin, C.; Rhodes, T.; Nardone, A.; Harris, M. A qualitative assessment of the acceptability of hepatitis $\mathrm{C}$ remote self-testing and self-sampling amongst people who use drugs in London, UK. BMC Infect. Dis. 2018, 18, 281. [CrossRef]

34. Hecht, R.; Hiebert, L.; Spearman, W.C.; Sonderup, M.W.; Guthrie, T.; Hallett, T.B.; Nayagam, S.; Razavi, H.; Soe-Lin, S.; VilakaziNhlapo, K.; et al. The investment case for hepatitis B and C in South Africa: Adaptation and innovation in policy analysis for disease program scale-up. Health Policy Plan. 2018, 33, 528-538. [CrossRef] [PubMed]

35. Majam, M.; Mazzola, L.; Rhagnath, N.; Lalla-Edward, S.T.; Mahomed, R.; Venter, W.D.F.; Fischer, A.E. Usability assessment of seven HIV self-test devices conducted with lay-users in Johannesburg, South Africa. PLoS ONE 2020, 15, e0227198. [CrossRef] [PubMed]

36. Brooke, J. SUS: A quick and dirty usability scale. In Usability Evaluation in Industry; Taylor and Francis: London, UK, 1996; pp. 189-194.

37. Kortum, P.; Peres, S.C. Evaluation of Home Health Care Devices: Remote Usability Assessment. JMIR Hum. Factors 2015, 2, e10. [CrossRef]

38. Gresenguet, G.; Dieu Longo, J.; Tonen-Wolyec, S.; Bouassa, R.-S.M.; Belec, L. Acceptability and Usability Evaluation of Finger-Stick Whole Blood HIV Self-Test as An HIV Screening Tool Adapted to The General Public in The Central African Republic. Open AIDS J. 2017, 11, 101-118. [CrossRef] [PubMed]

39. Bwana, P.; Ochieng, L.; Mwau, M. Performance and usability evaluation of the INSTI HIV self-test in Kenya for qualitative detection of antibodies to HIV. PLoS ONE 2018, 13, e0202491. [CrossRef] [PubMed]

40. Versfeld, A.; McBride, A.; Scheibe, A.; Spearman, C.W. Motivations, facilitators and barriers to accessing hepatitis C treatment among people who inject drugs in two South African cities. Harm Reduct. J. 2020, 17, 39. [CrossRef]

41. Smith, P.; Wallace, M.; Bekker, L.G. Adolescents' experience of a rapid HIV self-testing device in youth-friendly clinic settings in Cape Town South Africa: A cross-sectional community based usability study. JIAS 2016, 19. [CrossRef]

42. Blach, S.; Kondili, L.; Aghemo, A.; Waked, I.; Zeuzem, S.; Craxi, A. Impact of COVID-19 on global HCV elimination efforts. J. Hepatol. 2020, 31-36. [CrossRef]

43. Heffernan, A.; Cooke, G.S.; Nayagam, S.; Thursz, M.; Hallett, T.B. Scaling up prevention and treatment towards the elimination of hepatitis C: A global mathematical model. Lancet 2019, 393, 1319-1329. [CrossRef]

44. Mhango, M.; Chitungo, I.; Dzinamarira, T. COVID-19 lockdowns: Impact on facility-based HIV testing and the case for the scaling up of home-based testing services in sub-Saharan Africa. AIDS Behav. 2020, 24, 3014-3016. [CrossRef]

45. World Health Organisation. WHO Announces Development of New Guidance on Hepatitis C Self-Testing. Departmental News. Available online: https:/ / www.who.int/news/item/07-12-2020-who-announces-development-of-new-guidance-on-hepatitis-cself-testing (accessed on 7 December 2020). 